\title{
Evaluative Usage-based Metrics for the Selection of E-journals
}

\section{Karla L. Hahn and Lila A. Faulkner}

\begin{abstract}
To measure the value of print journals, librarians have gathered a range of statistics and developed a variety of metrics. Similar work to assess the value of e-journals has just begun. This article explores the usefulness of available e-journal usage statistics and develops three metrics and three benchmarks based on those metrics. The proposed metrics build on earlier work that assesses the value of print journals, although the earlier work is modified extensively to fit the e-journal arena. The ejournal statistics and metrics are further transformed to address a completely new area of application: the evaluation of potential purchases. Statistics and metrics are used to build three benchmark measures for assessing e-journal candidates for purchase. A comparison of Science and Nature site licenses illustrates the utility of the assessment benchmarks. The benchmarks, metrics, and statistics developed here provide a reliable framework for assessing both current collections and candidate collections of e-journals. Implications for standards development are clear; content measures are desperately needed for the development of an effective suite of e-journal statistics.
\end{abstract}

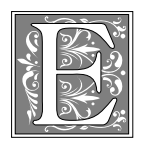

ven in the information age, the more things change, the more they remain the same. Librarians did not leave behind dramatically high serial prices with the conversion to electronic journals. If anything, the problem has worsened because many publishers seem to have used new electronic formats to justify even higher prices. With their budgets continually stretched tighter, librarians need to constantly evaluate their current collections and potential purchases to determine their value to the librarians' missions.

E-journals, however, present the same problems of valuation posed by print jour- nals. To assess the increasing prices of ejournals, librarians must find a way to compare journals with different amounts and quality of content, publishers, and subject matter. It is important to consider users and their demand for a particular journal. Who will use the journal? How often will they use it? Under what circumstances will they use it? E-journals further complicate the picture with complex pricing structures, online searching, hyperlinks, and server reliability. Regardless, the same problem of comparison remains: What a publisher charges for a particular journal does not necessarily reveal anything about its relative value.

Karla L. Hahn is the Collection Management Team Leader in the University of Maryland Libraries; email: kh86@umail.umd.edu. Lila A. Faulkner is the Electronic Publications Graduate Assistant in the University of Maryland Libraries; e-mail: lf71@umail.umd.edu. 
At first glance, this article's title presents a contradiction: How can usagebased indicators of value help librarians select resources not yet in the collection? The puzzle's answer lies in first developing metrics that indicate the value of current electronic resources based on the vendor's use and content data and then using those metrics to develop a set of benchmarks for the new resources. A series of calculations is needed to present a full picture of value in light of the price of the resource, the amount of content available, and the quantity of usage it receives. Although the metrics and benchmarks cannot provide an objective measurement of value, they do offer objective descriptive information useful for evaluating comparable resources.

In this article, the authors describe metrics developed to evaluate e-journals and to help librarians select additions to that collection. The first section reviews earlier efforts to assess the value of journals, both print and electronic. The next section explains the metrics created at the University of Maryland to assess value in the current collection there and the benchmarks designed to assist in selection. The metrics put the data provided by vendors on use into a context that allows librarians to compare the subscription prices and to assess the value of different journals. Finally, the article addresses the future of e-journal usage statistics.

\section{Foundations of Value Assessment}

This work continues a long struggle by librarians to measure the value of a journal. Unlike toasters or hammers, journals are not interchangeable, which makes simple cost comparisons difficult. World Politics and the American Journal of Political Science address the same audience, but no university library would attempt to persuade its political science faculty that only one title is needed. Even beyond uniqueness of content, other challenges make comparison difficult. One journal might contain one hundred large pages; another might contain two hundred smaller pages. Some journals offer news and job advertisements; others offer bibliographies or opinion pieces. One subscription offers twelve issues; another offers four.

Researchers have developed a number of analyses designed to address the task of determining the value of a print journal, to create what Barbara Meyers and Janice L. Fleming have referred to as a "reasonably equitable quantitative evaluation tool" to account for variations from title to title. ${ }^{1}$ Two primary approaches for assessing value have emerged. One examines price in the context of a journal's content. The best known of such studies is Henry H. Barschall's evaluation of the cost-effectiveness of physics titles, which analyzed cost per 1,000 characters and cost per impact factor to account for variations in the amount and quality of content. ${ }^{2}$ Following Barschall's example, other researchers have compared journals on the basis of price per 1,000 words, price per page, and cost per character. ${ }^{3}$ Most recently, the University of WisconsinMadison Libraries have updated Barschall's studies, using the same methodology.

The second major approach examines value in the context of use of the journal. Studies of the use of print journals have a long history. Although time-consuming, many libraries have nevertheless found such studies invaluable because the data can help identify potential cancellations, which faculty are more likely to support because the libraries are using the best data available. The University of Wisconsin-Madison Libraries have led the way in cost-per-use studies of print journals and have used their analyses to make journal cancellation decisions since $1995 .{ }^{5}$

A third approach provides a rare synthesis of the first two approaches. Carol Tenopir and Donald W. King discussed two metrics that reflect the value of the information in a journal: purchase value of a journal, based on the amount that researchers are willing to pay to use a journal, versus use value, based on the benefits that come from use. When the pur- 
chase value exceeds the use value, researchers turn away from subscriptions to alternative sources of journal articles. Tenopir and King have suggested that these metrics remain appropriate in the world of e-journals. ${ }^{6}$

Regardless of the method used, all researchers have agreed that a print journal's value cannot be assessed with content evaluation alone. Rather, the print journal's value must be put in the context of the amount of content it offers and the users it potentially serves. ${ }^{7}$ For example, if no one on a particular campus reads the articles in a particular journal, that journal has little value to the campus, even if the quality of its content is high. At the same time, use is not completely unrelated to either quality or quantity. For example, if a journal offers less content for the same price as its peers, that also must be taken consideration.

Although the need for context now seems like common sense in the print arena, surprisingly few researchers have applied lessons from the assessment of print journals to the e-journal or collections of e-journals. ${ }^{8}$ This shortcoming in the literature seems to stem, in part, from the focus on evolving standards for ejournal statistics rather than on their application. ${ }^{9}$ Instead of responding to the need for data to create effective metrics for assessing titles or collections, existing standards for e-journal statistics appear strongly derivative of database statistics. The standards demand counts of particular kinds of uses, but little information on the title or collection itself. For example, one does not see demands for data on the amount of content online for particular journals or collections that Barschall considered essential for determining the value of a print journal.

Without this information on electronic content, measures of the value of e-journals become difficult to create because the context needed to understand the available data is missing. The Council on Library and Information Resources's White Paper on E-journal Usage Statistics emphasized this need for context to evaluate usage statistics, but the need has yet to be translated into a demand for information on content to be included in online statistics. ${ }^{10}$ For example, the International Coalition of Library Consortia (ICOLC) guidelines recommend the provision of information on the number of queries, turn-aways, and items examined, but not on the type or amount of content currently offered online. ${ }^{11}$ Content measures are essential to both librarians and publishers seeking to interpret and apply usage data. Part of the problem with developing effective metrics lies in the lack of information on electronic content for particular journals or collections. Librarians cannot necessarily compile information on content themselves. The task of counting the number of articles, pages, or words for a particular e-journal or collections of e-journals can be overwhelming, and the amount of content in many collections changes constantly.

\section{The metrics allow equitable assess- ment of the e-journals' value in terms of both content offered and usage.}

Despite these difficulties, some currently available e-journal usage statistics illustrate new possibilities for assessing relative value and suggest how a broad set of usage statistics could be useful for collection management. Perhaps because usage statistics are hard to get, they have been more rarely factored into the valuations of e-journals than in print. However, usage becomes even more important to assessing value in the electronic arena because libraries often pay for access and not ownership. In the ownership context, libraries can purchase materials just in case they prove useful in the future; it makes little sense to spend funds on access that is not used.

A small body of work exploring usage statistics has only recently developed for e-journals, although the development of metrics to put that usage into the context of content remains unexplored. In a pioneering analysis of HighWire Press sta- 
tistics, Linda Mercer suggested applying electronic usage information to purchase and cancellation decisions, staff training decisions, and user studies. ${ }^{12}$ Deborah D. Blecic, Joan B. Fiscella, and Stephen Wiberley also explored the collection management implications of usage statistics, focusing on the potential for cancellation assessments. They noted that "If a library cannot afford to keep all titles, the question becomes, What percentage of use does the library want to meet? ... It can then ascertain the least expensive mix of titles that meets its goal and cancel the others." ${ }^{13}$ Although these discussions provide a starting point, a great deal of ground remains to be explored if e-journal assessment is to approach even the level of existing print journal assessments.

\section{Development of E-journal Metrics}

To create measures of value for e-journals, the authors of this article have carried the agreed-upon standard in the print world-Meyers and Fleming's "reasonably equitable quantitative evaluation tool" - into the electronic context. ${ }^{14}$ Building on earlier analyses examining cost per article, the authors have integrated the information provided by publishers on the usage of e-journals. In this way, the authors can not only assess the cost per unit of content, but also can examine what Mercer has called "performance measures" to determine the value that users derive from particular publications..$^{15}$ The result builds on studies of print journals and takes advantage of the ready availability of usage statistics for some e-journals. The analysis offers a way to measure the value of e-journals that incorporates both their relative content and the users' relative demand for them.

\section{Evaluation of Current Collections}

In the authors' analyses, the statistics provided by HighWire Press have proved the most valuable. ${ }^{16}$ HighWire Press provides a variety of statistics on use and the amount of content online for each title. A subset was used to develop the authors' metrics: HighWire Press's "number of full-text articles in HTML format viewed," its "number of PDF files downloaded," and the total articles online, in addition to the University of Maryland's subscription price. ${ }^{17}$ Articles are the primary unit of content measured for a title. The subset consists of the statistics that focus on the full text of articles because, for users, access to articles remains the primary benefit of online access. Users value the intellectual units found in journals - the articles, not particular words or pages. ${ }^{18}$

From the HighWire Press statistics, the authors derived three metrics to evaluate the value and the performance of licensed e-journals and collections of e-journals. Building on valuations commonly performed with print journals, the authors derived an average cost per access and an average cost per article. The average cost per access represents the average cost of each access event to a full-text article and is calculated from the e-journal's subscription price divided by the number of articles accessed. ${ }^{19,20}$

Average cost per access $=$ Subscription price Number of articles accessed

The average cost per article is computed by dividing the e-journal's subscription price by the total number of articles offered online by the e-journal.

Average cost per article $=$

Subscription price

Number of articles online

These metrics allow comparison of the value of e-journals with different online content and can indicate whether a site license is more cost-effective than the purchase of individual articles.

In addition to metrics adapted from existing print metrics, the authors developed a novel metric, content-adjusted usage, which allows the total number of articles offered online to be compared to the total number of HTML articles viewed and the total number of PDF files downloaded. This metric addresses the question, Out of the total articles offered by an e-journal, 
what proportion did our users access? Cost-adjusted usage is calculated by dividing the number of full-text accesses of an article (the number of times an HTML file is viewed or a PDF file is downloaded) by the number of available articles.

Content-adjusted usage $=$

Number of full-text accesses

Number of articles online

This metric provides a way to compare the usage of journals that offer widely differing numbers of articles online. For example, one learns little from discovering that, in 1999, the Journal of General Physiology (JGP) had thirty-eight full-text accesses and Pharmacological Reviews (PR) had twenty-eight full-text accesses unless one also knows that JGP offers 3,104 articles online and $P R$ offers only 543 articles. The metric indicates that JGP had a content-adjusted usage of 1.22 percent compared to $P R$ 's value of 5.16 percent, which puts $J G P^{\prime}$ s seemingly higher usage into perspective.

The metrics allow equitable assessment of the e-journals' value in terms of both content offered and usage. Usage adds a valuable dimension to the examination of relative value. For example, in 2000, these variables might have been used to examine the relative prices and performance of Journal of Cell Biology and Proceedings of the National Academy of Sciences (PNAS), both with annual subscription prices of $\$ 880$ for both print and online access. A first glance, it might seem that Journal of Cell Biology and PNAS offered similar value because their subscription prices were the same, but the numbers present a slightly more complicated picture. An examination of the titles' content-adjusted usage as of the end of 2000 revealed that only 4.9 percent of JCB's more than 13,500 full-text articles were displayed or downloaded compared to more than 19 percent of PNAS's more than 26,000 articles. Second, although $P N A S^{\prime}$ 's subscription price averaged out to $\$ .03$ per article online and $J C B$ provided articles online at a mere $\$ .07$ per article, a look at the average cost per access showed the numbers in a different light. PNAS's average cost per access at $\$ .17$ was only a little higher than its average cost per article whereas Journal of Cell Biology's average cost per access was $\$ 1.32$. Selectors could have used the results as a framework to begin examination of the worth of these e-journals in the context of their particular disciplines and user populations

As librarians receive appropriate usage statistics from more of their vendors, they can continue to create a landscape of acceptable prices and costs. The various statistics and metrics can be seen as mapping a multivariate space of products described by unique combinations of values such as price, article content, and usage. If librarians view their collections as mapping landscapes in the available space, they can more clearly assess where the boundaries lie for the values they define as reasonable. Items within the collection can be compared and items being considered for purchase can be evaluated based on whether they fit into the librarians' landscape of reasonable values or fall outside it. This concept of a multivariate landscape for value assessment offers a more sophisticated evaluative environment than the isolated application of single measures.

\section{Selection and Evaluation of Potential Purchases}

Traditionally, usage statistics have supported evaluations of past purchases, but descriptive statistics also can be transformed to produce three benchmarks for the evaluation of potential purchases. Two of the metrics already describedaverage cost per article and content-adjusted usage-can be used to create three new benchmark metrics for analyzing a potential purchase. The key to developing the evaluative benchmarks lies in the identification of comparable peer resources with known usage. Each benchmark uses data already known for both the product currently in the collection and the candidate purchase. This technique can be applied to the evaluation of a single e-journal title or an e-journal collection. 
Analysis of a potential purchase begins with a peer product already in the collection. The peer product should cover a similar subject area, address a like audience, and possibly share a history of comparable use as a print publication. Consider a hypothetical case where an e-journal collection is proposed for purchase. The collection under consideration, the Candidate Collection, is priced at $\$ 25,000$ per year and offers 45,000 articles online. The library already subscribes to a peer e-journal collection, the Licensed Collection. Last year, the Licensed Collection was priced at $\$ 10,000$ and experienced 25,000 full-text accesses. It contains 50,000 online articles in subject areas similar to the Candidate Collection. The titles in both collections are thought to have received similar usage in the past in print form. Table 1 illustrates the data known about the two collections.

To evaluate the Candidate Collection, the first step is to compare the two collections applying a metric already used to evaluate the past performance of licensed e-journals and collections-the averagecost-per-article metric. With a subscription price of $\$ 25,000$ and 45,000 articles, the Candidate Collection has an average cost per article of $\$ .55$, substantially higher than the Licensed Collection's average cost per article of $\$ .20$ for 50,000 articles at $\$ 10,000$. However, this alone may not be a fair basis of comparison between the collections. An article that re- ceives twice as much use as another might be worth twice the price. The more expensive articles also may provide enough value to justify the price. The benefit of the metric is that it quantifies the magnitude of the price differential for content alone. The selector still determines whether the differential is substantial enough to reject purchase or whether another resource might offer a better return on investment. Regardless, the single metric probably does not offer enough information to allow a fully informed decision. To aid selectors, the authors have developed three additional analyses in the form of benchmark metrics that incorporate assessments of likely usage levels: the cost-based usage benchmark, the content-based usage benchmark, and the cost per access at the content-based usage benchmark.

The cost-based usage benchmark determines how many full-text accesses a potential e-journal or collection purchase must receive in a year for it to achieve the same average cost per access as a peer ejournal or collection already licensed by the library. Using the previous examples of peer resources, the Candidate Collection and Licensed Collection, it is possible to determine how many full-text accesses the Candidate Collection would have to receive in order to attain the same value of cost per access as the Licensed Collection. In the past year, the Licensed Collection had 25,000 full-text accesses of its

\begin{tabular}{|lrr|}
\hline \multicolumn{3}{|c|}{ TABLE 1 } \\
Comparison of Candidate Collection to Licensed Collection \\
\hline \hline & $\begin{array}{r}\text { Licensed } \\
\text { Collection }\end{array}$ & $\begin{array}{r}\text { Candidate } \\
\text { Collection }\end{array}$ \\
\hline Price & $\$ 10,000$ & $\$ 25,000$ \\
Total number of online articles as of the end & 50,000 & 45,000 \\
of the year & & \\
Total annual number of full-text accesses to the & 25,000 & Unknown \\
articles in the collection & $\$ .20$ & $\$ .55$ \\
Average cost per article & 0.50 & Unknown \\
Content-adjusted use & $\$ .40$ & Unknown \\
Average cost per access & & \\
\hline
\end{tabular}


articles, giving it an average cost per access of $\$ .40$. The ultimate usage of the Candidate Collection is unknown. To estimate the level it must achieve to meet the value of the Licensed Collection, the average-cost-per-access metric is transformed into a benchmark and calculated in the following manner:

Cost-based usage benchmark $=$

Price of desired resource
Cost per access of peer
product in collection

To determine the cost-based usage benchmark for the Candidate Collection, the collection's price of $\$ 25,000$ is divided by the Licensed Collection's average cost per access of $\$ .40$, giving the Candidate Collection a cost-based usage benchmark of 62,500 uses. Therefore, for the Candidate Collection to achieve a cost per access level comparable to that of the Licensed Collection would require 62,500 full-text accesses in a subscription year, 37,500 more than the Licensed Collection's 25,000 full-text accesses. It is up to the selector to determine whether it is reasonable to expect use of the Candidate Collection to reach that level.

The second benchmark metric is the content-based usage benchmark. This metric determines how many full-text accesses a proposed purchase must receive in a year in order to provide the same value in terms of content-adjusted usage as a peer product currently in the collection. The metric allows the selector to assess the value of a proposed purchase from the further angle of the number of full-text accesses adjusted for collection size. Transforming the content-adjusted usage metric in the following manner creates the benchmark:

Content-based usage benchmark =

Collection Size x Content-adjusted

of Desired

Resource

Usage of Peer Product in Collection

Using the previous example, for the Candidate Collection to have a contentadjusted usage equivalent to the peer Licensed Collection, its 45,000 articles must reach the Licensed Collection's usage of 0.50 , or 50 percent. Therefore, the Candidate Collection would have a contentbased usage benchmark of 22,500 full-text accesses (equal to 45,000 articles multiplied by 0.50 uses per article). The selector then can consider whether the library can expect the Candidate Collection to provide a content-based usage value similar to the Licensed Collection.

The third benchmark metric is the cost per access at the content-based usage benchmark. This metric takes the content-based usage benchmark a step further by calculating the cost per access at that level of usage. For example, if the Candidate Collection were to achieve 22,500 accesses per year (equivalent to the Licensed Collection's content-based usage value of $0.50)$, its cost per access at the contentbased usage benchmark would be $\$ 1.11$, a rate that exceeds the Licensed Collection's cost per access by $\$ .71$.

The usage metrics (summarized in table 2) do not predict the level of usage but, rather, give selectors points of comparison for assessing the likelihood of the Candidate Collection providing value equivalent to or greater than the Licensed Collection. Together, the metrics provide a clearer picture of the levels of usage required for the Candidate Collection to provide usage value comparable to the existing investment made 


\begin{tabular}{|c|c|c|c|}
\hline \multicolumn{4}{|c|}{$\begin{array}{c}\text { TABLE } 3 \\
\text { Comparison of Science and Nature Site License Offers }\end{array}$} \\
\hline & $\begin{array}{l}\text { Science } \\
(2000)\end{array}$ & $\begin{array}{c}\text { Nature } \\
\text { (Fall 2000) }\end{array}$ & $\begin{array}{c}\text { Nature } \\
\text { (Spring 2001) }\end{array}$ \\
\hline Price & $\$ 5,500$ & $\$ 22,000$ & $\$ 6,500$ \\
\hline $\begin{array}{l}\text { Total number of online articles } \\
\text { as of end of year }\end{array}$ & 16,347 & $2,711^{*}$ & $30,000 * *$ \\
\hline $\begin{array}{l}\text { Total annual number of full-text } \\
\text { accesses to articles }\end{array}$ & 12,703 & Unknown & Unknown \\
\hline Average cost per article & $\$ .34$ & $\$ 8.12$ & $\$ .22$ \\
\hline Content-adjusted use & 0.771 & Unknown & Unknown \\
\hline Average cost per access & $\$ .43$ & Unknown & Unknown \\
\hline \multicolumn{4}{|c|}{$\begin{array}{l}\text { *Estimate based on the average number of articles published per month as reported for 1997-1999 } \\
\text { in Journal Citation Reports and extrapolated for the period of coverage of July } 1997 \text { through } \\
\text { December } 2001 \text { offered by Nature in its initial license. Journal Citation Reports counts only } \\
\text { research articles, not news reports, which corresponds to the content originally offered in the } 2000 \\
\text { Nature license pricing. }\end{array}$} \\
\hline $\begin{array}{l}* * \text { Based on estimates provided by } \mathrm{s} \\
\text { published in Nature, hence the subst }\end{array}$ & $\begin{array}{l}\text { The } 2001 \\
\text { nce in num }\end{array}$ & $\begin{array}{l}\text { nse offers full } \\
\text { of articles. }\end{array}$ & ess to all content \\
\hline
\end{tabular}

by the library in the Licensed Collection. The cost-based usage benchmark determines the amount of full-text accesses the untried product would need to receive to achieve a comparable cost per access. The contentbased usage benchmark examines how many full-text accesses the untried product must receive to experience comparable levels of usage per article. Assessing cost per access at the content-based usage benchmark helps put the content-based usage measure of value into perspective by calculating the average cost per access when a potential purchase achieves its content-based usage benchmark.

The metrics above provide objective points of comparison between e-journal products. They adjust for variations in pricing, collection size, and usage rates. The need to examine usage becomes particularly urgent when libraries purchase temporary access to, rather than ownership of, a resource. In contrast to print materials that can be purchased and stored until needed at a distant point in the future, the limited funds of most libraries make it unfeasible to pay for access year after year to materials that are not used. The metrics provide informa- tion to the collection manager while allowing him or her to determine acceptable levels of investment and anticipated usage. A selector could conclude that based on the comparability of the content in the Candidate Collection and the Licensed Collection, it is reasonable to expect comparable content-based usage. Further, the selector might be comfortable with the anticipated price differential of $\$ .71$ per access in the two collections.

A real-world analysis of information products illustrates the utility of this approach. The potential purchases are two Nature site licenses, offered at different times and varied in price and amount of online content. The licensed product is the online version of Science. All site licenses are based on the size of the user community at the University of Maryland. The prices used are rounded approximations of quotes offered to the University of Maryland, not the exact prices quoted. Because the two offers from Nature generate different evaluative metrics, this scenario maps an arresting assessment landscape. Tables 3 and 4 provide the statistics, metrics, and benchmarks for the three licenses. 


\begin{tabular}{|c|c|c|}
\hline \multicolumn{3}{|c|}{$\begin{array}{c}\text { TABLE } 4 \\
\text { Evaluative Metrics for Nature }\end{array}$} \\
\hline & $\begin{array}{c}\text { Nature } \\
\text { (Fall 2000) }\end{array}$ & $\begin{array}{c}\text { Nature } \\
\text { (Spring 2001) } \\
\end{array}$ \\
\hline Cost-based usage benchmark & 51,162 & 15,116 \\
\hline Content-based usage benchmark & 2,090 & 23,130 \\
\hline Cost per access at the content-based usage benchmark & $\$ 10.53$ & $\$ .28$ \\
\hline
\end{tabular}

At first glance, the initial Nature offer, the 2000 Nature License, would seem to provide less value than Science for Nature's subscription price of $\$ 22,000$. The 2000 Nature License's approximately 2,711 articles had an average cost of $\$ 8.12$ per article, almost twenty-four times the average cost of an article for Science at \$.34. To temper this comparison, however, Nature offered only those articles containing research content (albeit embargoed for three months) whereas Science's article count included news articles, book reviews, and editorials. Moving beyond the cost per article to content-based usage, the numbers appear less extreme. Science achieved a 0.77 , or a 77 percent, usage of its 16,347 articles in 2000 . Because the Nature 2000 License would give access to only 2,711 articles, Nature would require 2,090 full-text accesses to achieve similar content-based usage value to Science, but the cost per use at this level would be a whopping $\$ 10.53$ per access. To achieve the same cost per access as Science at \$.43, the 2000 Nature License would need 51,162 full-text accesses in a year, four times as much usage as Science received on campus in 2000.

In its second offer, the 2001 Nature License, Nature closed this disparity. The 2001 Nature License, with more than ten times as much content at a third of the price, had a price per article of $\$ .22, \$ .21$ lower than the cost of Science at $\$ .43$ per article. In addition, the type of content offered is more similar because the article count for both e-journals would contain news and opinion pieces as well as research articles. To achieve a similar content-based usage, because of the larger number of articles, Nature would require more full-text accesses for its 30,000 articles. It would have to have at least 23,130 full-text accesses to meet the usage level of Science of 0.77 , or 77 percent; however, the cost per access at that level would be only $\$ .28, \$ .15$ less than the current Science cost per access. To achieve a cost per access equal to that of Science, Nature need only receive 15,116 uses (1.19 times the usage of online version of Science in 2000).

If one assumes that the content-based usage benchmark sets a reasonable expectation of full-text access for Nature, the differences between the two offers become

\section{A high level of comparability maximizes the utility of the bench- mark metrics.}

clearer. The anticipated cost per use under the first Nature License would be more than twenty-four times the cost per access of Science articles in 2000 at the contentbased usage benchmark. Under the 2001 license terms, Nature articles would have a lower cost per access than Science articles at the content-based usage benchmark.

In the fall of 2000, a selector could evaluate the likelihood that Nature would receive four times the usage levels of $\mathrm{Sci}$ ence (assuming he or she wanted to achieve cost per use parity). Similarly, the selector could consider whether it is reasonable to pay an estimated $\$ 10.53$ per article if Nature sees usage at the per article level comparable to what has been observed in the recent past with the online version of Science. The benchmarks do not answer these questions, but they do provide a powerful framing system for evaluating selection decisions. The metrics can create a landscape of acceptable costs or, 
alternatively, a landscape of reasonable usage. The landscape, although useful, does not provide a directive for purchase; it simply provides a context for decisionmaking.

Some obvious questions remain. A major concern is the determination of an acceptable average cost per full-text access for any collection of articles. A number of factors could influence acceptable levels of cost in the electronic resource and print landscapes, such as budget levels or quality of content. What constitutes an acceptable level of usage, and thus acceptable benchmark usage levels, depends on the clientele of a library, the disciplinary focus of the content, the currency of the content, the perceived quality of the content, and a variety of other factors. Likewise, the setting of reasonable benchmarks of cost adjusted for content or use is context dependent. Available funding, availability of alternate information sources, level of need, or peculiarities of the local environment always contextualize such decisions.

Another key issue is the comparability of the peer resource in the collection to the purchase candidate. A high level of comparability maximizes the utility of the benchmark metrics. Peer resources should address similar subject areas. An e-journal in art could not develop useful benchmark metrics for a physics e-journal because it would not offer a realistic comparison. Peers also should have similar usage rates in print. Two physics ejournals with comparable usage rates in print could be expected to generate similar usage rates in electronic form. However, a variety of factors could alter the picture. It is not uncommon for electronic versions of print journals to offer a different amount of backfile or differ in the speed with which they load current issues. If users value access to current content highly, it might be worth paying a higher per article rate for more current content.

A third issue centers on the number of factors that can contribute to the levels of full-text access. Although the focus here is on a year's worth of data, a selector would ideally need to review a number of years of data to get a clear understanding of the usage levels for particular products. A new product typically will not reach ongoing usage for some period of time. In addition, a number of other factors can help increase or decrease usage levels. Marketing of electronic resources can affect their rate of adoption and ultimate use. As linkage between electronic resources becomes more frequent, it can enhance the rate of use of electronic resources.

A different concern affecting both the original usage metrics and the benchmarks is the challenge of quantifying either use or content. The proposed metrics use article access as a proxy for use and the article as the basic unit to measure content, but these units are somewhat arbitrary. Usage may reflect different activities with different resources. Some content providers offer different versions of their articles for printing and on-screen browsing. A user may access an article two or more times to use it once. Different content providers are likely to categorize different types of content as articles; for instance, letters, editorials, and news pieces might be counted in some resources and not in others. Articles can vary considerably in length.

Despite these questions, the metrics provide a powerful system for the evaluation of selection decisions. As information providers struggle to stretch their limited budgets, they must constantly reevaluate the value of their current collections and potential purchases. The metrics allow the selector to use known data to examine the full-text access and subscription price of both current items and potential purchases from a variety of angles. These data can reinforce the selector's subjective judgments on cancellation and purchase decisions. The usefulness of the data, however, depends on their availability in a consistent form from a variety of publishers so that selectors can create an assessment landscape that serves as a framework for their decisions. Demands for standards for publishers' 
usage statistics must begin to move beyond mere quests for data to the creation of standards that will advance the application of the statistics in collection management and other aspects of library administration.

\section{Conclusion}

This exploration of usage metrics and evaluative benchmarks suggests a world of possibilities and continuing conundrums in the search for measures of value to assist with collection development and management. Building on valuations of print journals, the authors have developed a variety of metrics to assess the value of e-journals and e-journal collections. The average cost per access, average cost per article, and content-adjusted usage allow the comparison of e-journals currently in the collection that have different amounts of online content. The cost-based usage benchmark, the contentbased usage benchmark, and the cost per access at the content-based usage benchmark allow the comparison of a currently held resource with a desired peer product, even if the products have different amounts of content and value. The metrics and benchmarks enhance the value and utility of the basic statistics provided by a publisher. Both provide decision support. The benchmarks take the metrics a step further and provide support for purchase decisions.

The creation of these metrics and benchmarks highlights a number of shortcomings in the usage statistics that publishers currently provide. First, because the metrics and benchmarks are built on the publisher's statistics, ambiguity and inconsistencies in the units counted pose real problems. It is not always clear what publishers count as an "article" or an "access." Fortunately, metrics do not have to be perfect to be helpful. Selectors constantly make qualitative and quantitative assessments based on imperfect information. Metrics need not provide absolute answers to collection development or collection management questions to help selectors make better decisions.
A larger problem is the paucity of needed statistics. For evaluative landscapes to develop, librarians must insist on statistics relevant to value assessment. The librarians' analysis demonstrates the critical need for content measures. Constantly changing amounts of content and collections holding thousands of articles prevent the authors from cost-effectively and reliably gathering their own data on content. Standards remain the best hope for information professionals to effectively communicate the statistics they need to publishers. It is therefore disappointing that e-journal statistics appear to still be mired in the measures of databases, largely conceptualized as electronic indexing and abstracting resources. Judy Luther is right to insist that context is essential to the interpretation of usage. ${ }^{21}$ The information community needs to determine what additional information can provide the needed context and insist that it be made explicit as part of the contract for access.

The metrics and benchmarks show that article counts can be used to enhance collection-building and management. That at least one publisher is already providing them suggests that counts could be easily made available. Indeed, article counts would only be a beginning; the literature on content measures for print journals suggest alternatives of counts of words or even characters. With developing e-publication standards such as XML, such counts should become feasible if they are not already. Further breakdowns of both content and usage measures are conceivable, such as usage of the current year's content or a comparison of the usage of research articles and editorials. The analyses presented here also demonstrate some approaches for more rational price development by publishers. As we begin to develop our first crude tools for evaluating electronic journals, it is satisfying to see their power, but daunting to recognize their crudeness. The metrics and benchmarks the authors have explored suggest the possibilities of what might be accomplished and suggest how much 
might be lost if librarians are unable to obtain the data they need to function as stewards for their collections and acquisitions budgets.

\section{Notes}

1. Barbara Meyers and Janice L. Fleming, "Price Analysis and the Serials Situation: Trying to Solve an Age-old Problem," Journal of Academic Librarianship 17, no. 2 (May 1991): 87, 86-92.

2. Henry H. Barschall, "The Cost of Physics Journals," Physics Today 39, no. 12 (Dec. 1986): 34-36; - "The Cost-Effectiveness of Physics Journals," Physics Today 41, no. 7 (July 1988): $56-59$.

3. For example, see American Mathematical Society, Journal Price Survey (1994-2001) (Providence, R.I.: American Mathematical Society, 2001), available online from <http:/ / www.ams.org/ membership/journal-survey.html>; Journal Price Study: Core Agricultural and Biological Journals (Ithaca, N.Y.: Faculty Taskforce, College of Agriculture and Life Sciences, Albert R. Mann Library, Cornell University, 1998), available online from <http://jan.mannlib.cornell.edu/jps/ jps.htm>; Meyers and Fleming, "Price Analysis and the Serials Situation."

4. George Soete, Measuring the Cost-Effectiveness of Journals: Ten Years after Barschall (Madison, Wis.: UW-Madison Libraries, 1999), available online from <http://www.library.wisc.edu/ projects/glsdo/cost.html>.

5. University of Wisconsin-Madison Libraries, Journals \& Journal Articles-Introduction (Madison, Wis.: UW-Madison Libraries, 2001), available online from <http:/ / www.wisc.edu/wendt/ journals/jintro.html>; University of Wisconsin-Madison Libraries, More Information about Journal Cost per Use Statistics (Madison, WI: UW-Madison Libraries, 1999), available online at <http:/ /www.wisc.edu/wendt/journals/costben/mcostben.html>.

6. Donald W. King and Carol Tenopir, "Designing Electronic Journals with 30 Years of Lessons from Print," JEP the Journal of Electronic Publishing 4, no. 2 (Dec. 1998), available online from $<$ http://www.press.umich.edu/jep/04-02/king.html>.

7. In If You Want to Evaluate Your Library (Champaign, Ill.: Univ. of Illinois, Graduate School of Library and Information Science, 1988): 8-9, F. W. Lancaster reflected this thinking in his discussion of one of Ranganathan's Five laws of Library Science: "Books Are for Use." Under this principle, libraries must consider the cost-effectiveness of their resources "because of limited resources, $\$ 30$ spent on a book that is little if ever used is $\$ 30$ less available for an item (possibly a duplicate copy) of something that might be in great demand."

8. An even larger question, which this analysis does not attempt to answer, is how to compare the value of print and electronic journals. As we develop means to more effectively assess and estimate the value of e-journals, it is also time to reassess the value of print journals with increasing subscription costs. As Suzanne D. Gyeszly has pointed out in "Electronic or Paper Journals? Budgetary, Collection Development, and User Satisfaction Questions," Collection Building 20, no. 1 (2001): 10, 5-10: "Until sufficient and standard use data are unavailable [sic], the library must pay for dual subscriptions for paper and online versions, as contracts with major e-journal providers such as Elsevier do not presently allow cancellation of paper subscription, despite heavy use of electronic subscriptions of the same title."

9. Pioneering work in the development of standard e-journal statistics, based on early work with the JSTOR project, has occurred under the auspices of the International Coalition of Library Consortia (ICOLC). See International Coalition of Library Consortia, Guidelines for Statistical Measures of Usage of Web-based Information Resources (December 2001 Revision of Original November 1998 Guidelines), available online from <http://www.library.yale.edu/consortia/ 2001webstats.html>. A more recent critique of e-journal statistics has been offered by Judy Luther in White Paper on Electronic Journal Usage Statistics (Washington, D.C.: Council on Library and Information Resources, 2000), available online from <http:/ / www.clir.org/pubs/reports / pub94/ contents.html>. The Association of Research Libraries funded the development of a set of metrics for electronic resources including e-journals. See Wonsick Shim, et al., Measures and Statistics for Research Library Networked Services: Procedures and Issues, ARL E-metrics Phase II Report (Washington, D.C.: Association of Research Libraries, 2001), also available online from <http:// www.arl.org/stats/newmeas/emetrics/phasetwo.pdf>.

10. Luther, White Paper on Electronic Journal Usage Statistics.

11. International Coalition of Library Consortia (ICOLC), Guidelines for Statistical Measures of Usage of Web-based, Indexed, Abstracted and Full-text Resources, available online from <http:// www.clir.org/pubs/reports/pub94/contents.html>.

12. Linda Mercer, "Measuring the Use and Value of Electronic Journals and Books," Issues in Science and Technology Librarianship, no. 25 (winter 2000), available online from <http:// 
www.library.ucsb.edu/istl/00-winter/article1.html>.

13. Deborah D. Blecic, Joan B. Fiscella, and Stephen Wiberley, "The Measurement of Use of Web-based Information Resources: An Early Look at Vendor-supplied Data Using ICOLC Guidelines," College \& Research Libraries 62, no. 5 (Sept. 2001): 450, 434-53.

14. Meyers and Fleming, "Price Analysis and the Serials Situation," 87.

15. Mercer, "Measuring the Use and Value of Electronic Journals and Books."

16. HighWire Press, the Internet imprint of Stanford University Libraries, hosts more than 250 science, technology, and medicine journals online. The home page for HighWire Press is located on the Web at <http:/ /highwire.stanford.edu $>$.

17. HighWire Press, Detailed Online Article Counts, available online from <http:// highwire.stanford.edu/lists/artcounts.dtl $>$, and Usage Statistics, available online from <http:/ / highwire.stanford.edu/lists/usage.dtl>.

18. Issue level data also might reflect a relevant unit of content for users, but these data were unavailable for analysis.

19. With the exception of Science, all the HighWire Press subscriptions include both print and online access for one price. This raises the dilemma of how to calculate an e-journal's subscription price. Several methods could be used, but what is important is to use a consistent approach. One sensible method is to use the price of the print/online bundle. Alternatively, when comparing online resources where access is priced independently of print subscription, as is the case with Science and Nature, the price of online access is the reasonable datum to use.

20. Note that the full-text accesses summarized in the attached statistics are not unique. An access event is counted regardless of whether it is to an article previously accessed or to a new article. For example, a single article in Science may be viewed in HTML format two times and downloaded as a PDF file once. Each of these accesses would be counted, giving a total of three "articles accessed."

21. Luther, White Paper on Electronic Journal Usage Statistics. 